Supporting Information For:

\title{
A Nickel Superoxide Dismutase Maquette That Reproduces The Spectroscopic and Functional Properties of the Metalloenzyme
}

Jason Shearer* and Linh M. Long

Department of Chemistry/216, University of Nevada, Reno, Reno, NV 89557

e-mail: shearer@chem.unr.edu

Contains:

Experimental Details.

Table S1. X-ray absorption refinement parameters.

Figure S1. HPLC of SODM1

Figure S2. ESI Mass spec of SODM1

Figure S3. $\mathrm{NiCl}_{2}-\mathrm{SOD}^{\mathrm{M} 1}$ titration curves

Figure S4. GPC data for [Nill(SODM1)]

Figure S5a/b. ${ }^{1} \mathrm{H}$ NMR spectrum of [Ni" $\left.\left(\mathrm{SOD}^{\mathrm{M}}{ }^{1}\right)\right]$

Figure S6. CD spectrum of [Ni"(SODM1] recorded from 260 - $185 \mathrm{~nm}$

Figure 7. [Ni"(SODM1)] XAS figures

Figure S8a/b. UV/Nis spectrum and photographs of SOD activity assay

Figure S9. Decomposition traces for [Ni" $\left(\mathrm{SOD}^{\mathrm{M}}\right)$ ] following $\mathrm{KO}_{2}$ addition

Figure S10. Peroxide assay for [ $\left.\mathrm{Ni}^{\prime \prime}\left(\mathrm{SOD}^{\mathrm{M} 1}\right)\right]$ following $\mathrm{KO}_{2}$ addition 


\section{Experimental}

[Ni"(SODM1)] Synthesis and Purification. SOD ${ }^{\mathrm{M} 1}$ ( $\left.\mathrm{H}_{2} \mathrm{~N}-\mathrm{HCDLPCGVYDPA}-\mathrm{COOH}\right)$ was prepared by solid phase synthesis on Wang resin using Fmoc based blocking strategies and HOBt/DIC coupling strategies. Following synthesis the peptide was cleaved from the resin using reagent $\mathrm{K}$. The cleavage solution was removed under high vacuum, and the resulting glassy crude peptide residue washed several times with freshly distilled diethyl ether. Following incubation at $45^{\circ} \mathrm{C}$ with a $10 \mathrm{mM}$ solution of $\beta$-mercaptoethanol, the crude peptide was purified by preparative reverse phase HPLC on a Waters Delta Prep 60 equipped with an Atlantis C18 column $(5 \mu \mathrm{m} ; 30 \times 100 \mathrm{~mm})$ using a linear gradient of $10-60 \% \mathrm{MeCN}$ in water $(0.1 \%$ TFA $)$ at $40 \mathrm{~mL} / \mathrm{min}$ over 45 minutes. The appropriate fractions were then lyophilized yielding a white powder. The purity of the peptide was then assessed by analytical HPLC using an Atlantis C18 column $(5 \mu \mathrm{m} ; 4.6 \times 100 \mathrm{~mm})$ and an identical gradient $(1 \mathrm{~mL} / \mathrm{min}$ flow rate). Incorporation of $\mathrm{Nill}$ into the peptides was performed anaerobically under basic conditions (100 mM sodium phosphate; $\mathrm{pH}=7.2$ ) by adding one equivalent of $\mathrm{NiCl}_{2}$ to $\mathrm{SOD}^{\mathrm{M} 1}$.

$\mathrm{Ni}$ titration studies. All $\mathrm{Ni}$ titration studies were performed anaerobically using a Varian Cary 50 spectrophotometer and $1 \mathrm{~cm}$ quartz cells. Solutions (100 mM sodium phosphate; $\mathrm{pH}=7.2$ ) of SODM1 ( 1.5 mM; concentration assessed by Ellman's test (Ellman, G. L. Arch. Biochem. Biophys. 1958, 74, 443-450.)) were prepared. Solutions of $\mathrm{NiCl}_{2}(100 \mathrm{mM}$ phosphate; $\mathrm{pH}=7.2)$ were then added to the peptide in increments of $0.01 \mathrm{mols}$ of $\mathrm{NiCl}_{2} /$ peptide until no further change in extinction coefficient was observed. A stoichiometry of $\sim 1 \mathrm{Nill}$ per peptide was based on the average of three data sets.

Gel permeation chromatography studies. Gel permeation chromatography studies were performed on a Waters Delta Prep 60 with analytical pump heads. A Waters Protein-Pak ${ }^{\mathrm{TM}}$ GPC column $(7.8 \times 300 \mathrm{~mm} ; 60 \AA$ A pore size) was utilized with a buffer flow rate of $1 \mathrm{~mL} / \mathrm{min}(50$ $\mathrm{mM}$ potassium phosphate; $\mathrm{pH}=7.5$ ). The buffer was maintained under a constant positive pressure of $\mathrm{He}$ and the absorbance at $350 \mathrm{~nm}$ was monitored (the apopeptide does not produce a significant response from the detector at this wavelength). The retention time of the metallopeptide was then plotted on a calibration curve made using a Waters Poly(ethylene glycol) molecular weight standards kit. calc: 1346.15 ; found: 1275 .

Electrochemical studies. Electrochemical data were recorded on a PARSTAT 2273 using a three electrode set-up (Carbon Fiber ultramicro-working-electrode; Pt auxiliary electrode; $\mathrm{Ag}$ / $\mathrm{AgCl}$ (sat. $\mathrm{NaCl}$ ) reference electrode) in a glass cell. The cell solution was $0.1 \mathrm{M} \mathrm{NaCl}(\mathrm{aq})$ with the $\mathrm{pH}$ adjusted to 7.2 using dilute $\mathrm{NaOH}$. This solution was rigorously degassed by sparging with dinitrogen prior to use. All electrochemical measurements were made in a Faraday cage to minimize noise in the CV. [Nill(SODM1)] was adhered to the electrode surface by applying $\sim 5$ $\mu \mathrm{L}$ of a $0.5 \mathrm{mM}$ solution of [Ni(SODM1)] $(\mathrm{pH} 7.2)$ to the freshly polished working electrode (10 $\mu \mathrm{m}$ radius) in a glove box under dinitrogen. After a short incubation time the excess solution was removed from the electrode surface. The working electrode was then placed in the cell and the potential held at $1.2 \mathrm{~V}$ vs. $\mathrm{Ag} / \mathrm{Ag}^{+}$for 60 seconds prior to recording the data. [Ni(SODM1)] appeared to stay absorbed to the electrode surface for $\sim 30 \mathrm{~min}$ following exposure to the cell solution, after which time no electrochemical response was obtained. We note that no oxidation or reduction waves are observed in this range when the apopeptide is used in these studies.

NBT/formazan and peroxide assays. In a typical experiment a $3 \mathrm{~mL}$ solution containing NBT $(33 \mu \mathrm{M})$ and freshly metalated [Ni(SODM1)] $(10 \mu \mathrm{M}, \mathrm{pH} 7.20 .01 \mathrm{M}$ sodium phosphate buffer) 
was prepared. Solid $\mathrm{KO}_{2}$ (between $6.5 \mathrm{mg}$ (1400 eq. per mol of NBT) to $70 \mathrm{mg}$ (15500 eq. per mol of NBT)) was then added to the solution portion-wise and the UV/Vis spectrum recorded after bubbling had ceased (5 - 20 seconds later depending on the amount of $\mathrm{KO}_{2}$ added). Control experiment were performed in an identical manner omitting [ $\mathrm{Ni}\left(\mathrm{SOD}^{\mathrm{M} 1}\right)$ ] from the solution or utilizing either: $\mathrm{NiCl}_{2}, \mathrm{SOD}^{\mathrm{M} 1}$, or the metal complexes [Ni(bmedach)] or $\left(\mathrm{NEt}_{4}\right)_{2}[\mathrm{Ni}$ (emi)], instead of [Ni(SOD $\left.\left.{ }^{\mathrm{M} 1}\right)\right]$. [Nill(bmedach)] was solubilized with a minimal amount of DMF prior to dilution and addition to the NBT mixture. The concentrations of the control compounds were $10 \mu \mathrm{M}$ in all cases.

A peroxide assay kit from Biomedical Research Services (SUNY Buffalo; Cat\# A-109) was used to probe $\mathrm{H}_{2} \mathrm{O}_{2}$ production by $\left[\mathrm{Ni}\left(\mathrm{SOD}^{\mathrm{M} 1}\right)\right]$. The assay was modified as follows. $10 \mu \mathrm{L}$ of assay solution I was added to $100 \mu \mathrm{L}$ of assay solution II. A $10 \mu \mathrm{L}$ aliquot of a standard hydrogen peroxide solution was added to this mixture. The assay solution was then diluted to $500 \mu \mathrm{L}$. After $15 \mathrm{~min}$. the UV/Vis spectrum was recorded using a $1 \mathrm{~cm}$ pathlength microvolume cuvette. A calibration curve was made by monitoring the change in absorbance at $552 \mathrm{~nm}$ following the addition of known concentrations of $\mathrm{H}_{2} \mathrm{O}_{2}$ to the assay solutions. For the reaction between [Ni(SODM1)] and $\mathrm{KO}_{2}, 100$ eq. of $\mathrm{KO}_{2}$ was added to $10 \mathrm{~mL}$ of a $0.1 \mathrm{mM}$ solution of [Ni (SODM1)]. Once the bubbling had ceased the solution was diluted 25 fold and a $10 \mu \mathrm{L}$ aliquot analyzed as above. All experiments were performed in triplicate.

X-ray absorption studies. A $2.5 \mathrm{mM}$ solution of [Nill(SODM1)] was injected into an aluminum sample holder between windows made from Kapton tape (3M, cat. no. 1205; Minneapolis, MN) and quickly frozen in liquid nitrogen. Data were collected at the National Synchrotron Light Source (Brookhaven National Laboratories; Upton, NY) on beamline X9b. A focused Si(111) double monochrometer was used for energy selection along with a low-angle Ni mirror for harmonic rejection. Energy calibrations were performed by recording a reference spectrum of $\mathrm{Ni}$ foil (first inflection point assigned to $8331.6 \mathrm{eV}$ ) simultaneously with the samples. All samples were maintained at $20 \mathrm{~K}$ throughout the data collection using a helium Displex cryostat. The spectra are reported as fluorescence data, which were recorded utilizing a 13-element Ge solidstate fluorescence detector (Canberra). Total count rates were maintained under $40 \mathrm{kHz}$ per channel, and a deadtime correction of $3 \mu \mathrm{s}$ was utilized (this had a negligible influence on the data). For edge spectra the primary hutch aperture height was set to $0.4 \mathrm{~mm}$ to obtain the maximum spectral resolution (theoretical maximum is $\sim 0.7 \mathrm{eV}$ ), and data were obtained in 10 $\mathrm{eV}$ steps in the pre-edge region $(8131-8310 \mathrm{eV}), 0.3 \mathrm{eV}$ steps in the edge region $(8310-8350$ $\mathrm{eV})$, and $2.0 \mathrm{eV}$ steps in the near-edge region. For EXAFS spectra the primary hutch aperture was set to $0.8 \mathrm{~mm}$ and data were obtained in $5.0 \mathrm{eV}$ steps in the pre-edge region $(8131-8310$ $\mathrm{eV}), 0.5 \mathrm{eV}$ steps in the edge region $(8310-8350 \mathrm{eV}), 2.0 \mathrm{eV}$ steps in the near-edge region $(8352-8630 \mathrm{eV})$, and $5.0 \mathrm{eV}$ steps in the far-edge region $(8631 \mathrm{eV}-15.5 \mathrm{k})$. All spectra represent the averaged sum of three data sets.

Data analysis was performed with the XAS refinement package EXAFS123 provided by Prof. Robert C. Scarrow (Haverford College; Haverford, PA; The details of this package can be found in: Egdal et. al. J. Am. Chem. Soc. 2003, 125, 32 - 33 and references provided in the supporting information of that article). We present refinements based on Fourier Filtered $k^{3}$ data: FT from $2.2-14.5 \AA^{-1}$; backtransformed from $1.0-2.5 \AA^{-1}$. All of the nomenclature used conforms to generally accepted usage based on the recommendations of the International Workshops on Standards and Criteria in XAFS (Bunker, G., Hasnain, S., Sayers, D., Eds. In X-ray Absorption Fine Structure; Hasnain, S. S., Ed.; Ellis Horwood: New York, 1991). 
Table S1. EXAFS refinements for the best fit to [Nill(SOD $\left.{ }^{\mathrm{M} 1}\right)$ ] by both restraining the $\mathrm{N}$ and $\mathrm{S}$ scatterers and letting them remain free. Best fits in the text are based on restrained refinements.

\begin{tabular}{|c|c|}
\hline Peak or shell & metric parameter \\
\hline Pre-edge Peak 1 & $\begin{array}{l}\text { Energy }=8332.9(4) \mathrm{eV} \\
\text { Peak area }^{\mathrm{a}}=0.03(1) \mathrm{eV}^{-1}\end{array}$ \\
\hline Pre-edge Peak 2 & $\begin{array}{l}\text { Energy }=8337.8(1) \text { eV } \\
\text { Peak area }^{a}=0.41(3) \mathrm{eV}^{-1}\end{array}$ \\
\hline Pre-edge Peak 3 & $\begin{array}{l}\text { Energy }=8339.5(2) \mathrm{eV} \\
\text { Peak area }^{\mathrm{a}}=0.10(2) \mathrm{eV}^{-1}\end{array}$ \\
\hline Pre-edge Peak 4 & $\begin{array}{l}\text { Energy }=8346.3(2) \mathrm{eV} \\
\text { Peak area }^{\mathrm{a}}=0.12(1) \mathrm{eV}^{-1}\end{array}$ \\
\hline $\mathrm{N}$ & $\begin{array}{l}n=2 \\
r=1.93(2) \AA \\
\sigma^{2}=0.009(2) \AA^{2} \\
E_{o}=8349.8 \mathrm{eV}\end{array}$ \\
\hline S & $\begin{array}{l}n=2 \\
r=2.180(2) \AA \\
\sigma^{2}=0.0023(2) \AA^{2} \\
E_{o}=8349.8 \mathrm{eV}\end{array}$ \\
\hline GOFb & 0.66 \\
\hline $\mathrm{N}$ & $\begin{array}{l}n=3.1(12) \\
r=1.94(3) \AA \\
\sigma^{2}=0.008(4) \AA^{2} \\
E_{o}=8349.8 \mathrm{eV}\end{array}$ \\
\hline $\mathrm{S}$ & $\begin{array}{l}n=1.2(9) \\
r=2.186(9) \\
\sigma^{2}=0.001(2) \AA^{2} \\
E_{o}=8349.8 \mathrm{eV}\end{array}$ \\
\hline GOFb & 0.47 \\
\hline
\end{tabular}

a: Peak area relative to the edge.

b: GOF $=R[n\{\operatorname{idp}\} /(n\{\mathrm{idp}\}-n\{\mathrm{p}\})] 1 / 2 \quad R=$ ave[(data-simulation)/esd(data); $n(p)=$ number of varied paramters; $\quad n(i d p)=2\left(r_{\max }-r_{\min }\right)\left(k_{\max }-k_{\min }\right) / \pi$ 


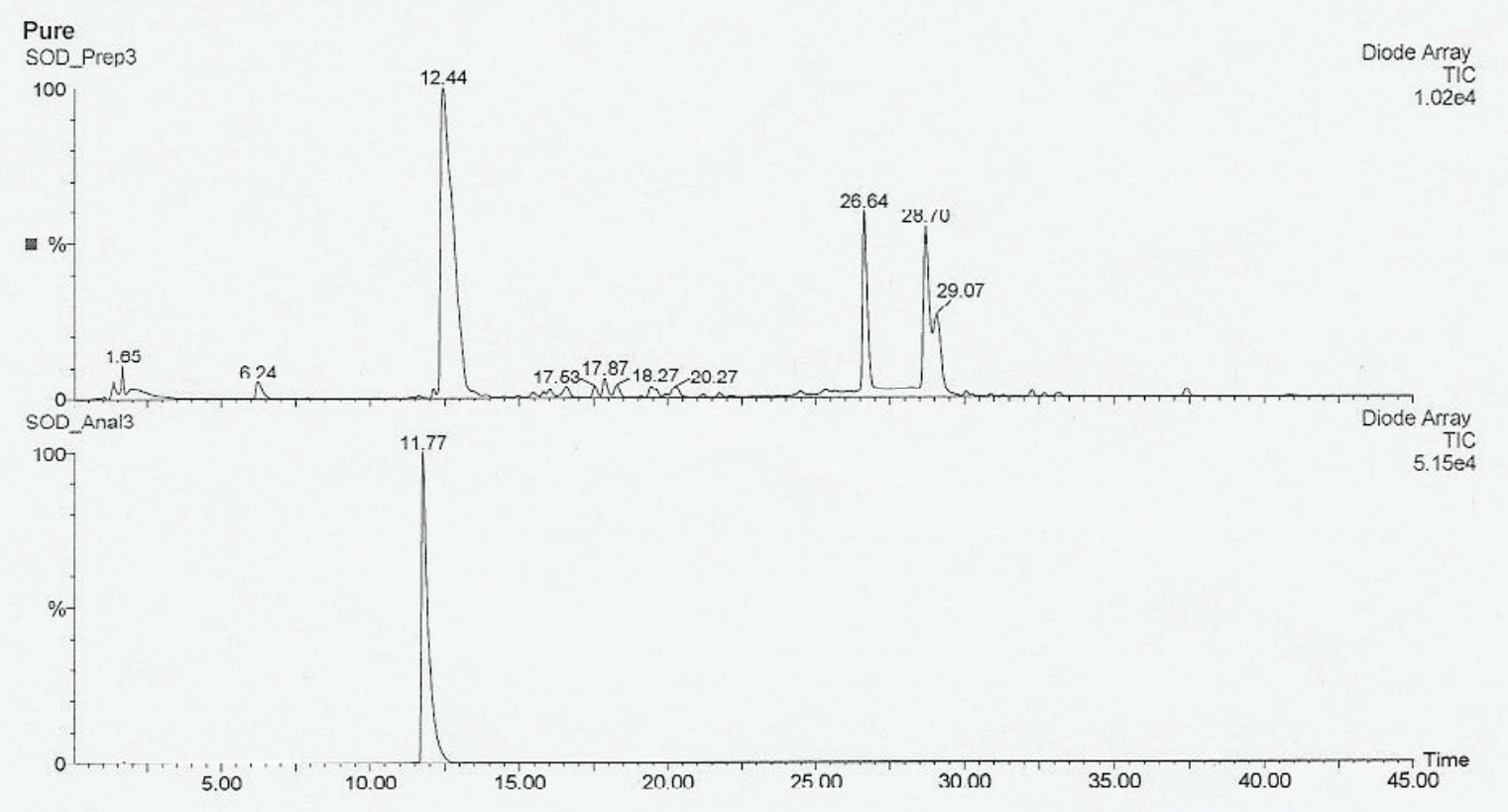

Figure S1. Preparative (top) and analytical (bottom) reverse phase HPLC chromatogram of SODM1. The peak at $12.44 \mathrm{~min}$ in the preparative run (11.77 min in the analytical run) was identified as SODM1, and was collected and lyophilized. An Atlantis $\mathrm{C}_{18}$ column (Water Corp.; Milford, MA) was used for both preparative $(30 \times 100 \mathrm{~mm})$ and analytical $(4.6 \times 100 \mathrm{~mm})$ chromatograms. For each run water/acetonitrile $(0.1 \% \mathrm{v} / \mathrm{v}$ trifluroacetic acid in both) was used with a linear gradient of $90 \% / 10 \% \rightarrow 40 \% / 60 \%$ over $45 \mathrm{~min}$. 


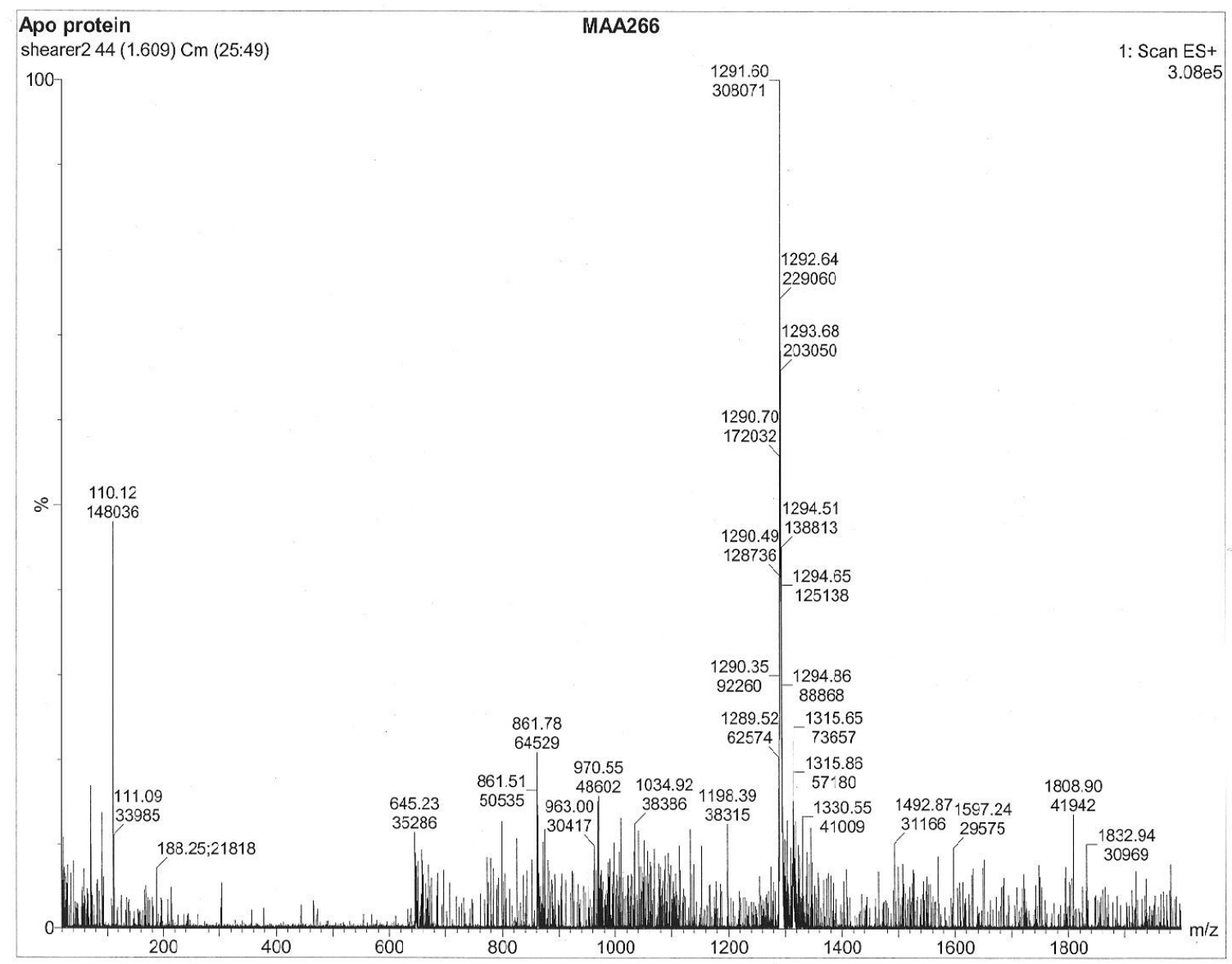

Figure S2. ESI mass spectrogram of SOD ${ }^{\mathrm{M} 1}$. 


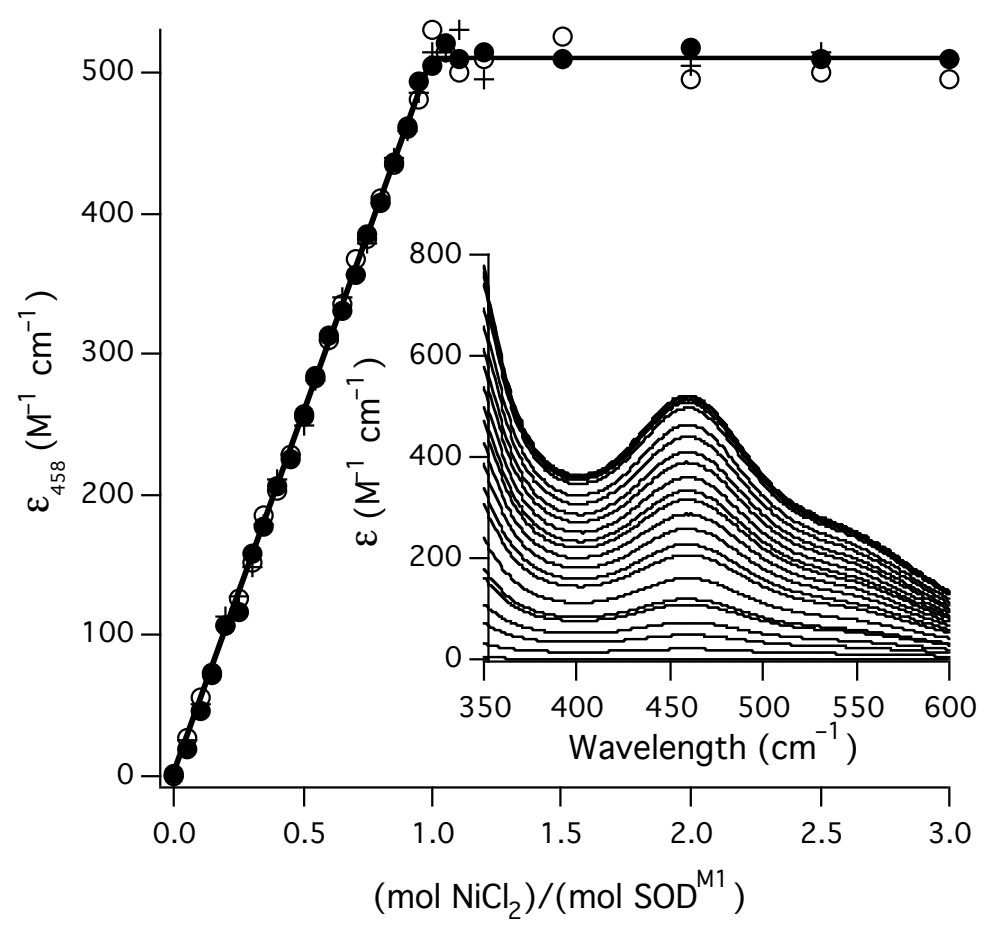

Figure S3. Titration curves for $\mathrm{NiCl}_{2}$ addition to $\mathrm{SOD}^{\mathrm{M} 1}$ following the increase of the peak at $458 \mathrm{~nm}$. For all curves a $0.1 \mathrm{M}$ phosphate buffer $(\mathrm{pH}=7.2)$ was used. An average over three trials of $1.02(3)$ eq. of $\mathrm{NiCl}_{2}$ per SODM1 was required to reach the end point. Inset depicts the UV/Vis spectral changes from a representative run.

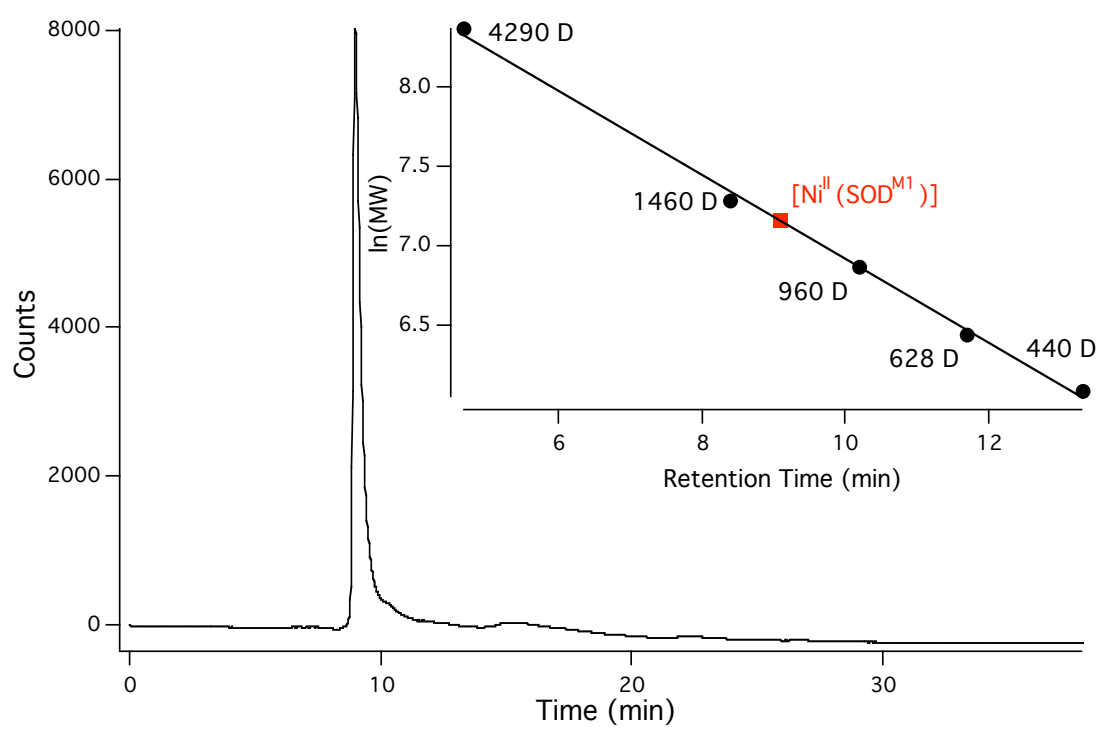

Figure S4. Gel permeation chromatogram for [Nill(SODM1)]. Inset depicts: the calibration curve (black line), molecular wight vs. retention times for standards (black circles) and where [Ni" $\left(\mathrm{SOD}^{\mathrm{M} 1}\right)$ ] falls on the calibration curve (red square). 


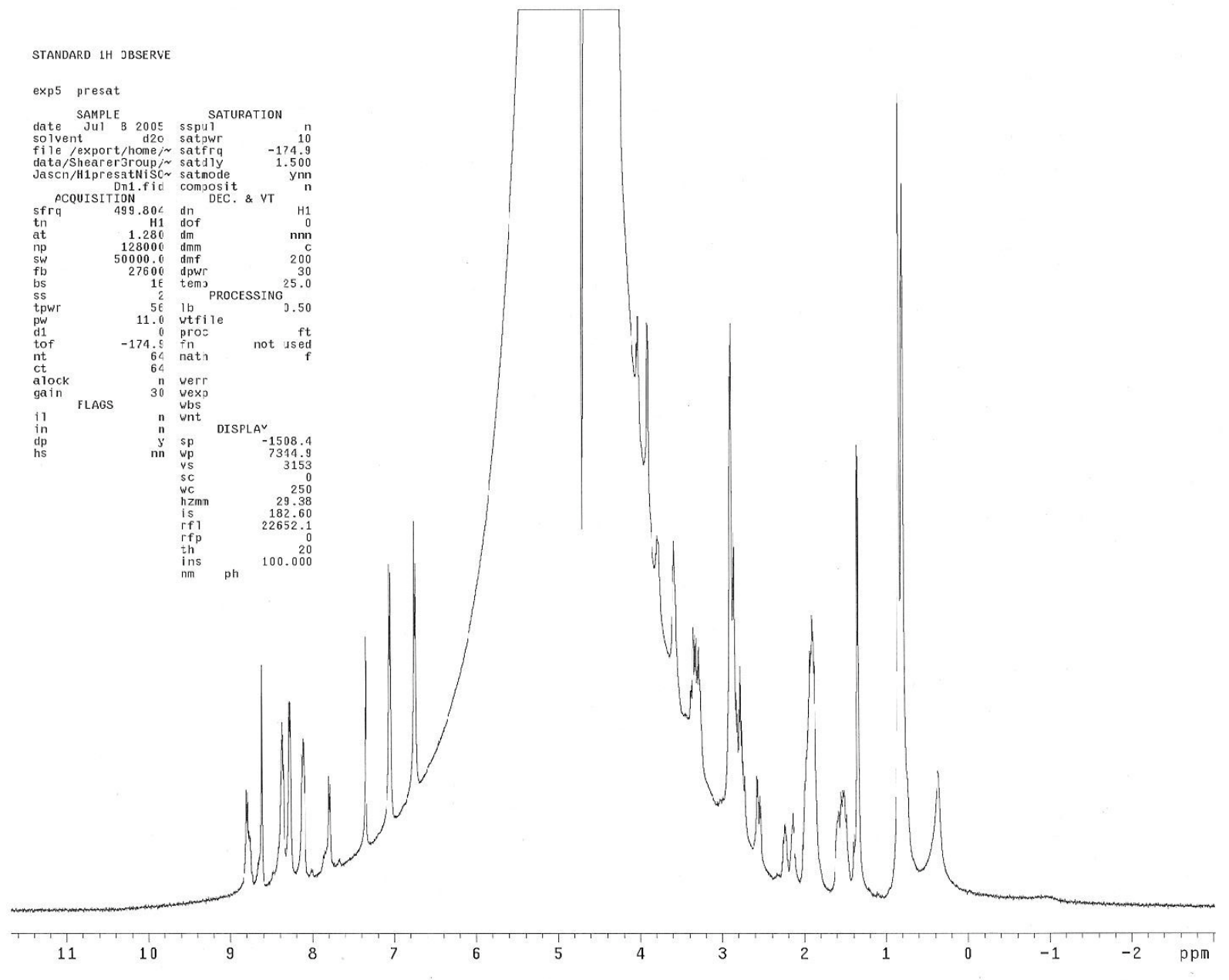

Figure S5a. ${ }^{1} \mathrm{H}$ NMR spectrum of [Nill(SODM1)] recorded in 9:1 $\mathrm{H}_{2} \mathrm{O}: \mathrm{D}_{2} \mathrm{O}$ at $25^{\circ} \mathrm{C}(\mathrm{pH}=7.5$ adjusted by $\mathrm{NaOH}$ ). The water peak was suppressed using presaturation pulse. 


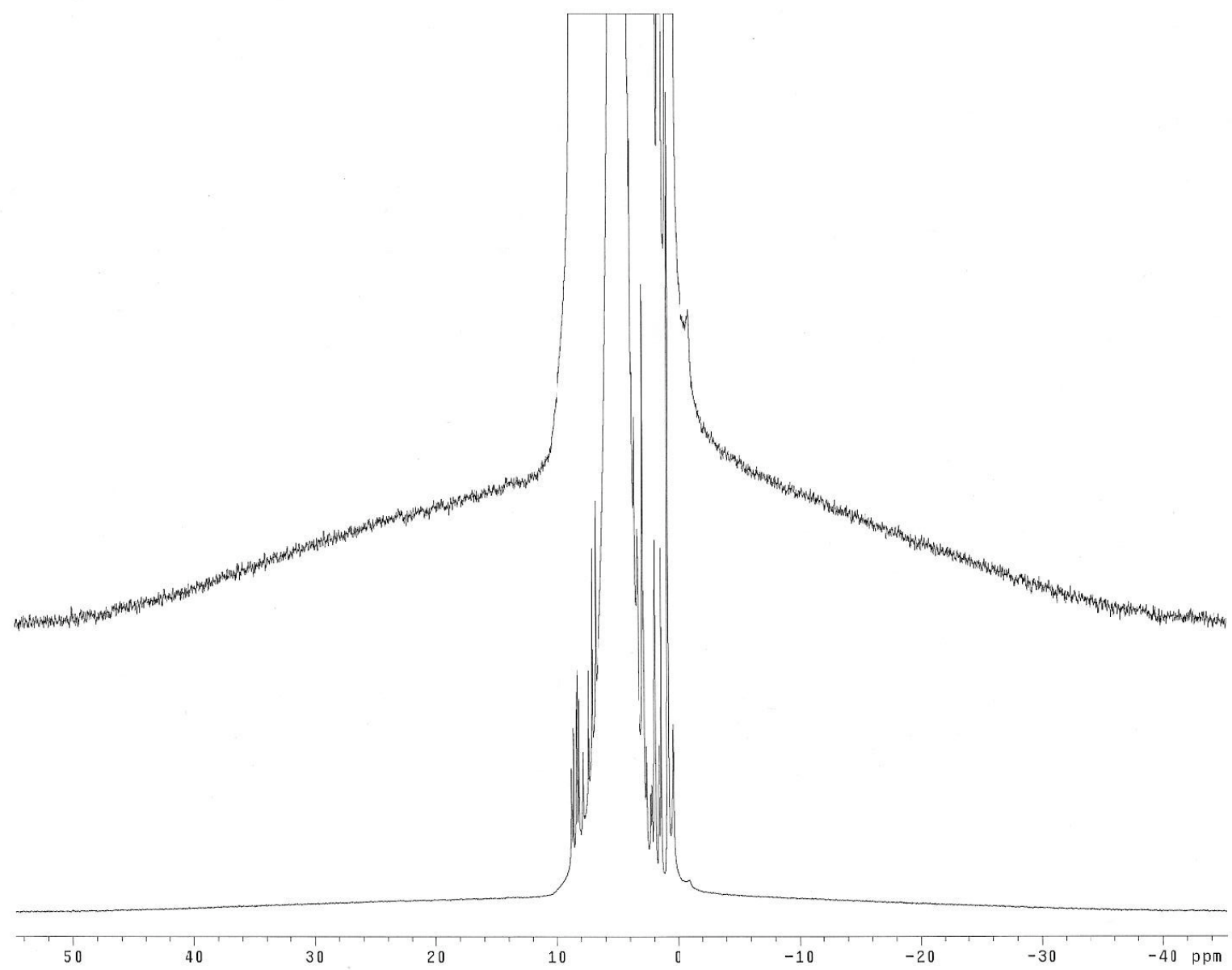

Figure S5b. ${ }^{1} \mathrm{H}$ NMR spectrum of [Nill(SODM1)] recorded in $9: 1 \mathrm{H}_{2} \mathrm{O}: \mathrm{D}_{2} \mathrm{O}$ at $25^{\circ} \mathrm{C}(\mathrm{pH}=7.5$ adjusted by $\mathrm{NaOH}$ ) expanded with a $20 \mathrm{~Hz}$ line broadening applied to identify any broad paramagnetic peaks buried in the baseline. 


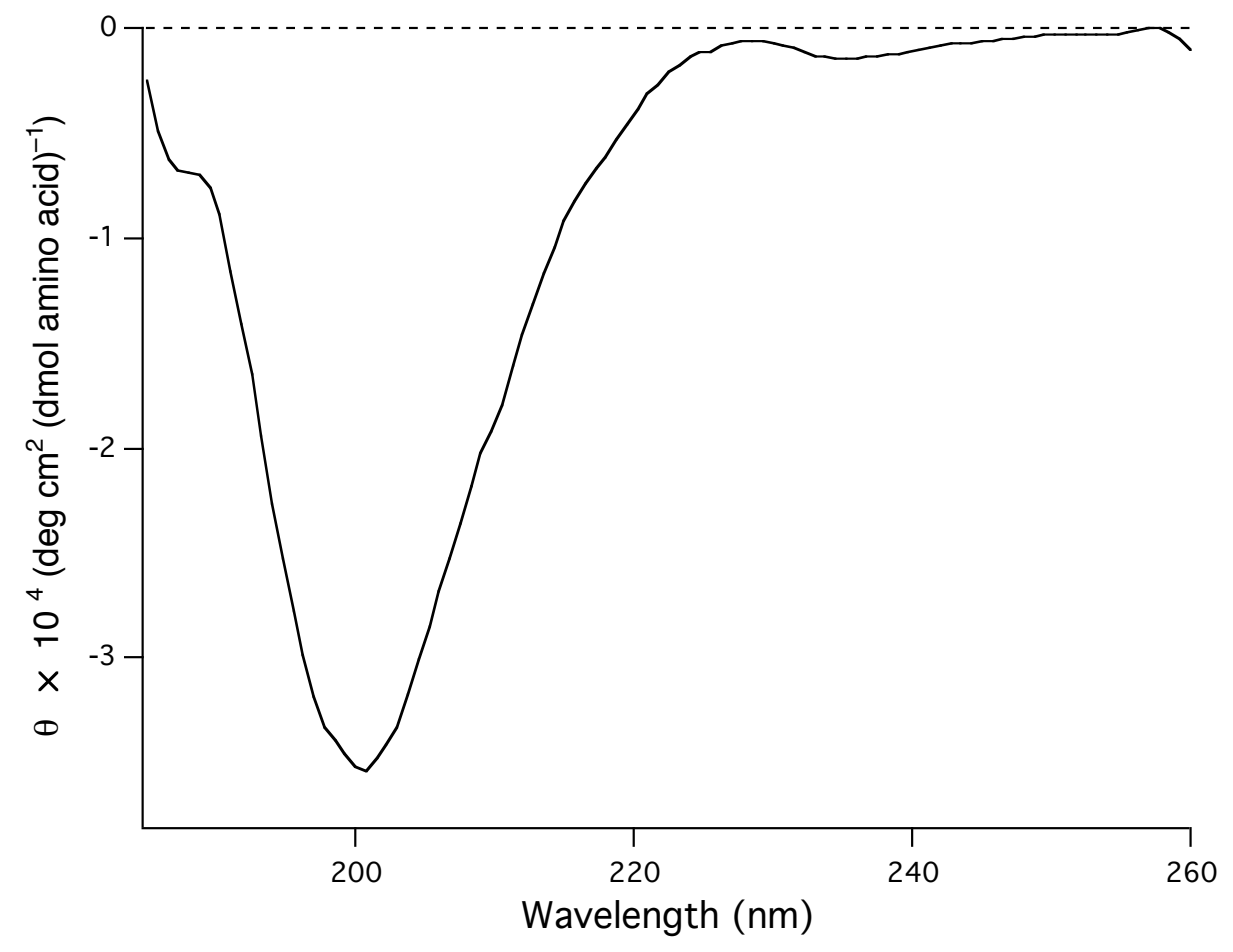

Figure 6. CD spectrum (185- $260 \mathrm{~nm})$ of [ $\left.\mathrm{Nill}^{\prime \prime}\left(\mathrm{SOD}^{\mathrm{M} 1}\right)\right]$. Recorded at room temperature at $\mathrm{pH}$ $=7.2$ in sodium phosphate buffer $(0.1 \mathrm{M})$. The spectrum was recorded in a cell with a path length of $1 \mathrm{~mm}$ using $1 \mathrm{mg}$ of metallopeptide per $\mathrm{mL}$ of solution.
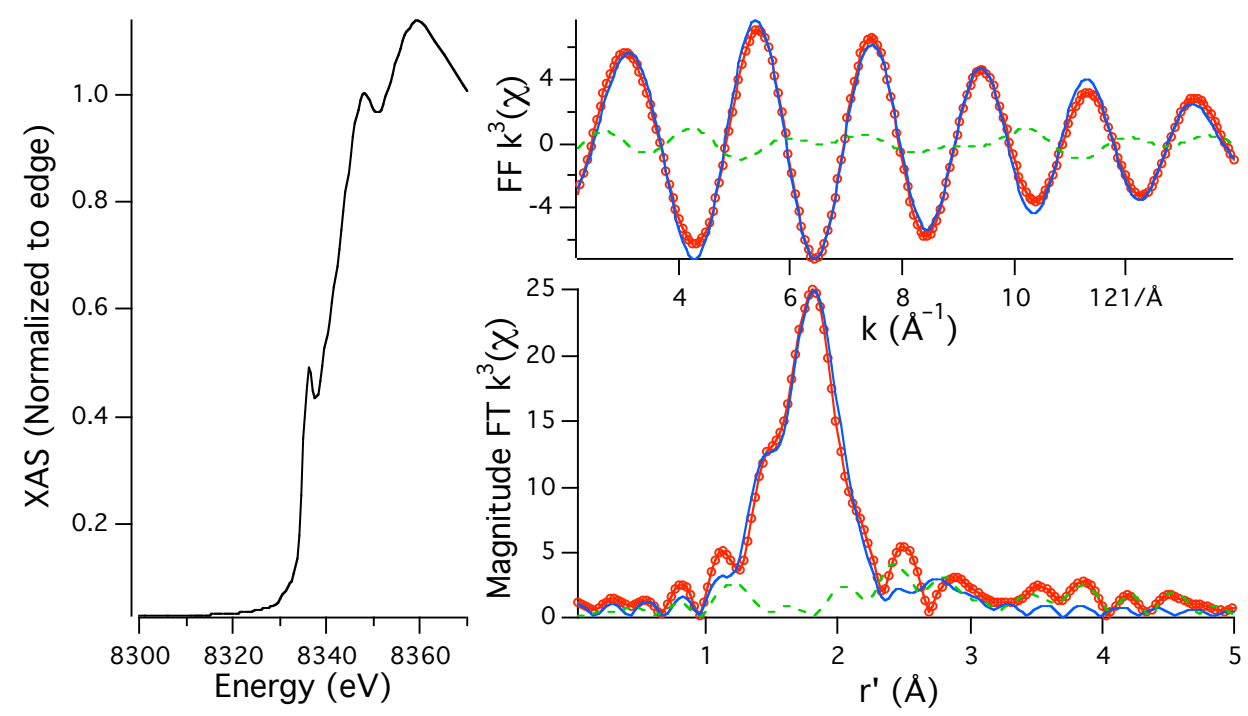

Figure S7. Left depicts the edge region of the Ni K-edge XAS for [Nill(SODM1)]. The bottom right is the Magnitude FT $k^{3}$ EXAFS while the top right is the FF $k^{3}$ EXAFS. The real data is plotted in red, the best fit is in blue, and the difference spectrum is plotted in green. 


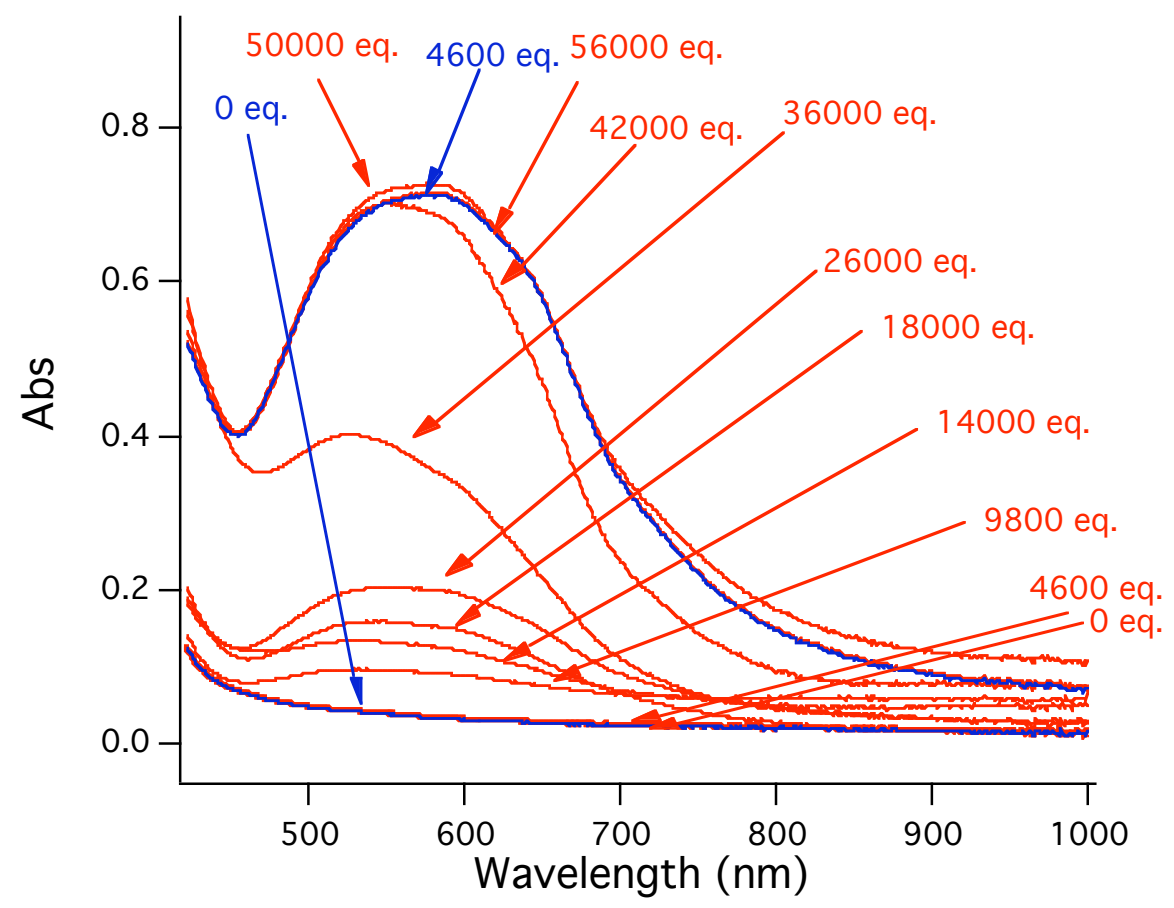

Figure S8a. Representative UV/Vis spectrum showing the effects of $\mathrm{KO}_{2}$ addition to solutions of NBT (blue) and [Ni(SODM1)]/NBT (red). The appearance of the broad peak at $~ 580 \mathrm{~nm}$ is characteristic of formazan, which is the product of the NBT reaction with superoxide. The study was performed at $20(1)^{\circ} \mathrm{C}$ in a $0.1 \mathrm{M}$ phosphate buffer at $\mathrm{pH}=7.2(33(1) \mu \mathrm{M} N B T, 10(1) \mu \mathrm{M}[\mathrm{Ni}$ $\left.\left.\left(\mathrm{SOD}^{\mathrm{M} 1}\right)\right]\right)$.

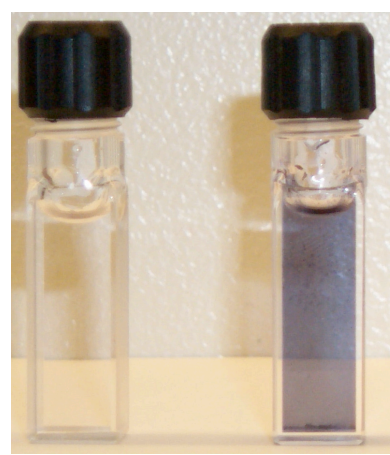

(1)
(2)

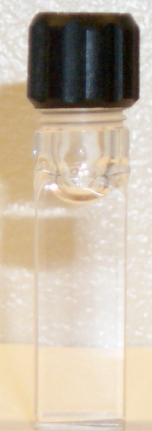

(3)

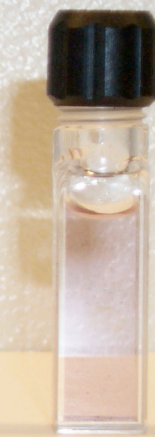

(4)

Figure S8b. Photograph of SOD activity studies from above. (1) NBT before $\mathrm{KO}_{2}$ addition. (2) $\mathrm{NBT}+4600$ eq. of $\mathrm{KO}_{2}$. (3) $\mathrm{NBT} /\left[\mathrm{Ni}\left(\mathrm{SOD}^{\mathrm{M} 1}\right)\right]+4600$ eq. of $\mathrm{KO}_{2}$. (4) NBT/[Ni(SOD$\left.\left.{ }^{\mathrm{M} 1}\right)\right]+9800$ eq. of $\mathrm{KO}_{2}$. 


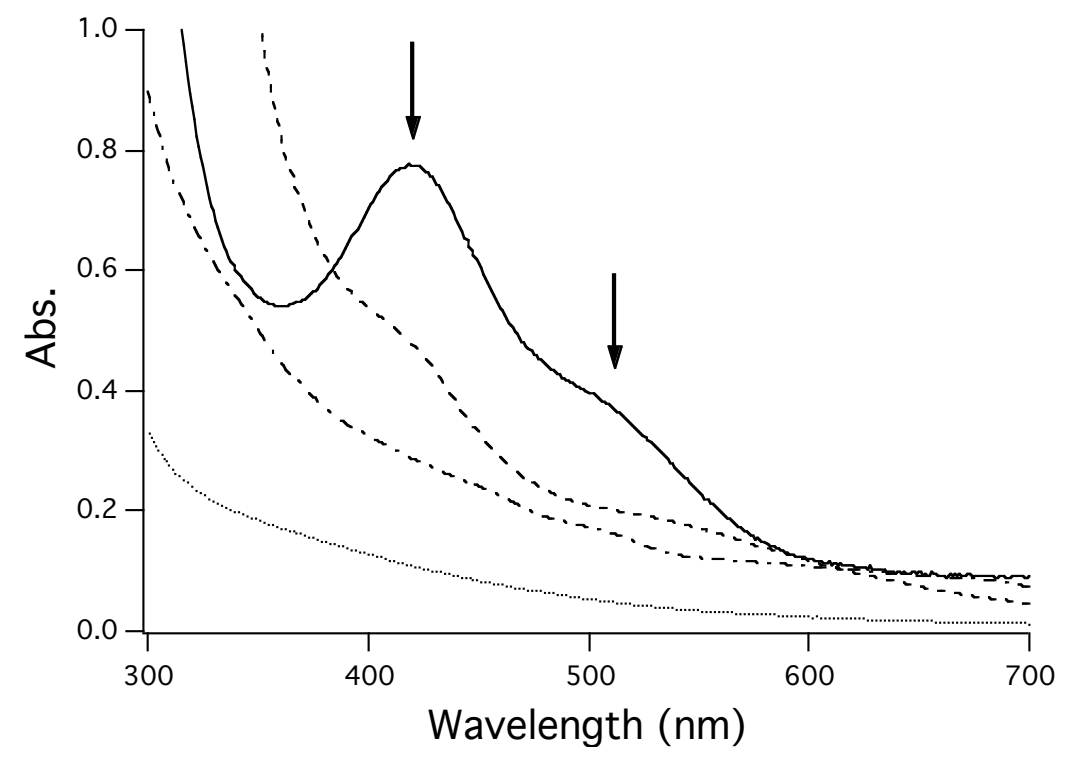

Figure S9. Decomposition of [Nill(SOD $\left.\left.{ }^{\mathrm{M} 1}\right)\right]$ following the addition of 50 eq. of solid $\mathrm{KO}_{2}$. Traces depict the UV/Vis spectrum of the reaction just prior to $\mathrm{KO}_{2}$ addition (solid line), 30 seconds after the addition of $\mathrm{KO}_{2}$ (dashed line), 90 seconds after the addition of $\mathrm{KO}_{2}$ (long and short dashed line), and 300 seconds after the addition of $\mathrm{KO}_{2}$ (dotted line).

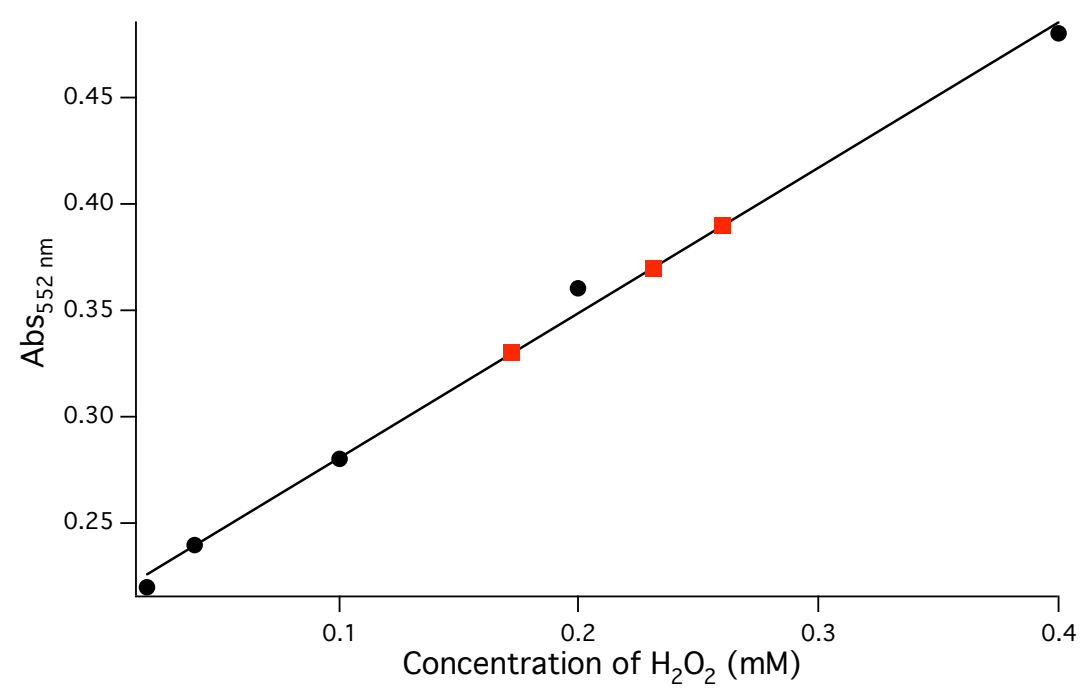

Figure S10. Results from the peroxide assay. The black dots represent the averages of three assays using known concentration of $\mathrm{H}_{2} \mathrm{O}_{2}$ added to the assay solution (concentration added is given along the y axis) while monitoring the absorbance at $552 \mathrm{~nm}$. The red squares represent the absobance obtained for aliquots from the reaction between $\mathrm{KO}_{2}$ and [Nill(SODM1)] (calc. 0.20 $\mu \mathrm{M}$; found: $0.22(2) \mu \mathrm{M})$. 